\title{
Autoimmune Anti-HIV-1gp120 Antibody with Antiidiotype-like Activity in Sera and Immune Complexes of HIV-1-related Immunologic Thrombocytopenia
}

Simon Karpatkin and Michael Nardi

New York University Medical School, Department of Medicine, New York 10016

\begin{abstract}
Autoimmune antiidiotype-like antibody (Ab2) directed against anti-HIV-1gp120 (Ab1) was found in high titer in the sera of 10 consecutive homosexual and 11 narcotic addict HIV-1-related immunologic thrombocytopenia (HIV-1-ITP) patients, was barely detectable in 10 nonthrombocytopenic HIV-1 sero-positive individuals, and was not detectable in 5 normal subjects by use of a solid-phase RIA. Reactivity of autologous Ab2 for Ab1 was 4-120-fold greater than Ab2 for homologous Ab1. Affinity-purified $\mathrm{Ab2}$ did not block the binding of affinity-purified Ab1 to its HIV-1gp120 epitopes on immunoblot, indicating the absence of "internal image" antiidiotype. Both Ab1 and Ab2 are precipitable from sera with polyethylene glycol (PEG) and present in a macromolecular complex that is excluded by gel filtration on G200 and contains IgG, IgM, C3, and the antiF(ab')2 antiidiotype-like complex. PEG-precipitable complexes bind to platelets in a saturation-dependent manner. Neither affinity-purified Ab1 nor Ab2 binds to platelets. However, the combination of $\mathrm{Ab1}$ and $\mathrm{Ab2}$ (preincubated for $2 \mathrm{~h}$ at $22^{\circ} \mathrm{C}$ ) binds to platelets in a saturation-dependent manner at an optimum ratio range of 10-20:1. Ab2 reactivity correlates with serum PEG-precipitable immune complex level $(r=0.91 ; P$ $<0.001)$ and with thrombocytopenia $(r=0.89 ; P<0.001)$. We suggest that the anti-HIV-1gp120 antiidiotype-like complex contributes to the markedly elevated platelet Ig and $\mathrm{C} 3$ level of HIV-1-ITP patients and propose that this may contribute to their thrombocytopenia. (J. Clin. Invest. 1992. 89:356-364.) Key words: HIV-1-ITP • platelets • immune complexes • antiF(ab')2 antibody • antiidiotype HIV-1gp1 20 antibody
\end{abstract}

\section{Introduction}

Immunologic thrombocytopenia (ITP) ${ }^{1}$ is a frequent complication of HIV-1 infection in homosexuals (1), intravenous nar-

This work was presented in part at the American Society of Hematology meeting in Atlanta, GA on 4 December 1989. Portions of this work have appeared in abstract form (1989. Blood. 74[Suppl. 1]:128A).

Address reprint requests to $S$. Karpatkin, Department of Medicine, New York University Medical School, New York, NY 10016. 1991.

Received for publication 27 July 1990 and in revised form 4 October

1. Abbreviations used in this paper: Ab1, anti-HIV-1gp120 antibody; Ab2, antiidiotype-like antibody; ATP, autoimmune thrombocytopenia; HIV-1-ITP, HIV-1-related ITP; HSITP, homosexual patient with ITP; ITP, immunologic thrombocytopenia; NITP; narcotic drug addict patient with ITP.

J. Clin. Invest.

(C) The American Society for Clinical Investigation, Inc. 0021-9738/92/02/0356/09 \$2.00

Volume 89, February 1992, 356-364 cotic addicts (2), and hemophiliacs receiving antihemophilic factor concentrates (3). Platelet immune complex deposition (4-6) and specific antiplatelet antibody $(2,7-9)$ have been reported as possible etiologic agents.

We have previously reported the presence of anti- $\mathrm{F}\left(\mathrm{ab}^{\prime}\right)_{2}$ antibodies in the sera and polyethylene glycol (PEG)-precipitable immune complexes of HIV-1-ITP patients that correlated with the level of PEG-precipitable immune complexes (5). In addition, we found anti-HIV-1 antibody on platelets of HIV-1ITP patients that eluted as a high-molecular-weight complex on gel filtration (6). Since HIV-1 antigen or proviral DNA was not detectable in platelet eluates or extracts, we postulated the presence of an autoantiidiotype to anti-HIV-1 antibody.

In this report we use a highly sensitive quantitative immunoassay to document the presence of autoimmune antiidiotype-like antibody $(\mathrm{Ab} 2)$ against $\mathrm{F}\left(\mathrm{ab}^{\prime}\right)_{2}$ fragments of affinitypurified anti-HIV-1gp120 antibody (Ab1) in the sera of 10 homosexual and 11 narcotic addict HIV-1-ITP patients. Both $\mathrm{Ab} 1$ and $\mathrm{Ab} 2$ are PEG-precipitable and present within a macromolecular complex containing IgG, IgM, and C3. Ab2 reactivity correlates inversely with platelet count. Although neither $\mathrm{Ab} 1$ nor Ab2 alone binds to platelets, the complex of both antibodies binds in a saturation-dependent manner.

\section{Methods}

Population. The population studied consisted of 59 HIV-1-seropositive patients: 29 homosexuals (24 with idiopathic thrombocytopenia [HSITP] and 5 with normal platelet counts), 30 intravenous narcotic addicts (25 with idiopathic thrombocytopenia [NITP] and 5 with normal platelet counts), 14 classic autoimmune thrombocytopenia (ATP) patients, and 14 healthy control subjects.

Purified IgG. Purified IgG was prepared from serum by ion exchange chromatography (5).

$F\left(a b^{\prime}\right)_{2}$ fragments. $\mathrm{F}\left(\mathrm{ab}^{\prime}\right)_{2}$ fragments were prepared from purified IgG as previously described (5): pepsin digestion, followed by dialysis against PBS, followed by affinity chromatography on insoluble staphylococcal protein $A$. The identity of the nonadherent purified $F\left(a^{\prime}\right)_{2}$ was verified by SDS-PAGE as well as by immunoassay performed with rabbit anti-human IgG-Fc antibody (5).

Immune complexes. Immune complexes were prepared from serum by PEG precipitation (5). Precipitates were dissolved in one-fifth the usual volume, $\sim 2-4 \mathrm{mg} / \mathrm{ml}$. Immune complexes were gel filtered (see below) and the exclusion volume isotopically labeled with ${ }^{125} \mathrm{I}$ by the Iodogen method (Sigma Chemical Co., St. Louis, MO).

Gel filtration. Gel filtration was performed on Sephadex G-200 as previously described (4). Effluents were assayed for protein at $280 \mathrm{~nm}$ as well as ELISA HIV-1 OD at $\mathbf{4 0 5} \mathrm{nm}$.

$H I V-1$ antibody. HIV-1 antibody was detected by a solid-phase absorption, ELISA assay using the HIV Ab HIV-1 EIA kit (Abbott Laboratories, North Chicago, IL), as recommended by the manufacturer. Briefly, 5-10 serial dilutions of sample were incubated with HIV-1coated beads at $40^{\circ} \mathrm{C}$ for $1 \mathrm{~h}$, washed in water, incubated with anti-human IgG $(H+L)$ coupled to horseradish peroxidase for $2 \mathrm{~h}$ at $40^{\circ} \mathrm{C}$, washed, and incubated with substrate for $30 \mathrm{~min}$ at room temperature; the reaction was stopped with $1 \mathrm{~N} \mathrm{H}_{2} \mathrm{SO}_{4}$. The linear portion of the 
logarithmic curve of HIV OD versus dilution was utilized for test measurements.

Affinity chromatography of PEG-precipitable immune complexes. 1 $\mathrm{ml}$ of immune complexes, solubilized in PBS- $0.02 \%$ azide $(0.7 \mathrm{mg} /$ $\mathrm{ml}$ ), was applied to $1 \mathrm{ml}$ of each of the following insoluble slurry: staphylococcal protein A on Sepharose CL4B (Sigma Chemical Co.); rabbit anti-IgM ( $\mu$-chain specific, Organon Teknika, Westchester, PA), $4 \mathrm{mg}$ coupled to $1 \mathrm{ml}$ of Affi-Gel 10; and goat anti-human anti-C3 (Organon Teknika), $2.4 \mathrm{mg}$ coupled to $1 \mathrm{ml}$ of Affi-Gel 10 (Bio-Rad Laboratories, Richmond, CA). Slurries were equilibrated in PBS before addition of sample and gently rocked overnight at $4^{\circ} \mathrm{C}$. The slurry was then centrifuged at $100 \mathrm{~g}$ for $10 \mathrm{~min}$ at room temperature and the supernatant removed for testing. Bound material was washed five times with PBS, five times with PBS- $0.2 \mathrm{M} \mathrm{NaCl}$, and another five times with PBS; eluted with $0.1 \mathrm{M}$ glycine buffer, $\mathrm{pH} 2.5$; and neutralized with $1 \mathrm{M}$ Tris buffer. Effluent samples were compared with original samples with respect to HIV-1 OD reactivity and binding to platelets. The fraction of the antibody removed by adsorption was calculated by comparison of the slopes of the linear portion (five to six serial dilutions) of the binding curve before and after adsorption to the affinity matrix.

Binding of PEG-precipitable immune complexes or affinity-purified antibodies to platelets on microtiter plates. Washed platelets were prepared from EDTA-anticoagulated blood as described (10) and $10^{7}$ platelets applied to U-shaped wells of a polyvinyl microtiter plate (Dynatech Laboratories, Inc., Alexandria, VA) for $1 \mathrm{~h}$ at room temperature. Plates were blocked and washed three times in 3\% Blotto-0.02\% azide (11) and then reacted with test sample. Nonadherent test sample was washed away; the adherent sample reacted with ${ }^{125}$ I-labeled staphylococcal protein A and washed; and wells were monitored for reactivity (see below under RIA for cross-reactive Ab2).

Binding of ${ }^{125}$ I-labeled PEG-precipitable immune complexes to platelets. Washed platelets $\left(1.2 \times 10^{6}\right)$ were applied to microtiter plates, blocked, and washed as above. They were then treated with serial dilutions of ${ }^{125}$ I-labeled solubilized immune complex $\left(8.4 \times 10^{6} \mathrm{cpm} / \mu \mathrm{g}\right)$ starting at $200 \mathrm{ng} /$ well or a 100:1 mixture of nonradioactive/radioactive immune complex starting at $2,000 \mathrm{ng} /$ well for $2 \mathrm{~h}$ at room temperature. Finally, wells were washed and monitored for radioactivity. Binding of ${ }^{125}$ I-labeled solubilized immune complexes to blocked microtiter plates in the absence of platelets was negligible $(50-100 \mathrm{cpm})$.

Binding of HIV-1 antibody of PEG-precipitable immune complexes to platelets in suspension. Washed platelets $\left(3.75 \times 10^{8}\right)$ were suspended in $250 \mu$ l of serially diluted solubilized PEG-precipitable immune complexes or $7 \mathrm{~S} \mathrm{IgG} \mathrm{(starting} \mathrm{at} 0.5 \mathrm{mg} / \mathrm{ml}$ ) and incubated for 3 $\mathrm{h}$ at $22^{\circ} \mathrm{C}$, followed by overnight incubation at $4^{\circ} \mathrm{C}$. Similar results are obtained in the absence of overnight incubation at $4^{\circ} \mathrm{C}$. The suspension was then applied to $4 \mathrm{ml}$ of a $20 \%$ sucrose cushion and centrifuged at $12,350 \mathrm{~g}$ for $10 \mathrm{~min}$ at $4^{\circ} \mathrm{C}$ to separate bound from unbound ligand. Control experiments, with addition of $0.5 \mathrm{mg} / \mathrm{ml}$ of immune complex to the sucrose cushion in the absence of platelets, revealed no detectable Ab1 activity at the tip of the test tube in $250 \mu$ l, after centrifugation. The sucrose was removed, the platelets were suspended in $250 \mu \mathrm{l}$ of PBS, and the bound Abl eluted by addition of $125 \mu \mathrm{l}$ of $150 \mathrm{mM}$ $\mathrm{H}_{3} \mathrm{PO}_{4}, 100 \mathrm{mM} \mathrm{NaCl}$, and $1.5 \% \mathrm{BSA}, \mathrm{pH} 2.8$ for $10 \mathrm{~min}$, with shaking at $37^{\circ} \mathrm{C}$. The acidified suspension was centrifuged at $20,000 \mathrm{~g}$ and neutralized with $2.5 \mathrm{M}$ Tris buffer to $\mathrm{pH}$ 8.0.50 $\mu$ l of this solution was then assayed for Abl reactivity by HIV-1 ELISA assay.

Affinity-purified Abl. Recombinant gp120 of the HIV-1 envelope glycoprotein was kindly supplied by Dr. Scott D. Putney (Repligen Corp., Cambridge, MA) and designated PB1-IIIB. $2 \mathrm{mg}$ was coupled to Affi-Gel 10. The gel was incubated with $\sim 20 \mathrm{mg}$ of purified $\mathrm{IgG}$ from $1 \mathrm{ml}$ of HIV-1-positive serum overnight at $4^{\circ} \mathrm{C}$. The gel was then washed extensively with five bed volumes of $0.01 \mathrm{M} \mathrm{PBS,} \mathrm{pH} \mathrm{7.4,} \mathrm{five}$ washes of PBS- $0.5 \mathrm{M} \mathrm{NaCl}$, and five washes of PBS. Abl was eluted with $0.1 \mathrm{M}$ glycine, $\mathrm{pH} 2.5$, monitored by $280-\mathrm{nm}$ absorption, and immediately neutralized to $\mathrm{pH} 7.4$ with $1 \mathrm{M}$ Tris buffer. $1 \mathrm{ml}$ of serum with a titer of $>1: 2,000$ provided $\sim 200-400 \mu \mathrm{g}$ of antibody. Specificity for gp120 was verified by immunoblot on nitrocellulose strips impregnated with multiple HIV-1 antigens (Epitope, Beaverton, OR). Al- though multiple bands were noted with HIV-1-positive sera, only one band was noted at the gp1 20 region with Ab1 (6). A standard curve was constructed for HIV-1 OD versus IgG protein, which was linear with a $\log -\log$ plot. The sp act of three different affinity-purified preparations averaged $0.050 \mathrm{OD} / \mathrm{ng} \operatorname{IgG}(6)$.

$\mathrm{Abl}$ was also prepared from PEG-precipitable immune complexes by a strategy described for anti-F( $\left(\mathrm{ab}^{\prime}\right)_{2}$ antibodies (5). Briefly, the gp 120 Affi-gel affinity column was acidified to $\mathrm{pH} 2.5$ with $0.1 \mathrm{M}$ glycine buffer and mixed with immune complexes similarly acidified. The slurry was slowly neutralized by dialysis overnight against PBS- $0.02 \%$ azide. By this method the solid-phase gp120 competes for the dissociated $\mathrm{Abl}$ of the immune complex as the $\mathrm{pH}$ is raised. The solid-phase matrix was then washed and eluted as above.

Affinity-purified Ab2. Ab2 was prepared by coupling affinity-purified Abl $(0.6 \mathrm{mg})$ to an Affi-Gel 10 column. Purified IgG from $1 \mathrm{ml}$ of patients' sera was adsorbed, washed, and eluted as above. $1 \mathrm{ml}$ provided $\sim 20 \mu \mathrm{g}$ of $\mathrm{Ab} 2$. Specificity was verified by reactivity with $\mathrm{F}\left(\mathrm{ab}^{\prime}\right)_{2}$ frag-

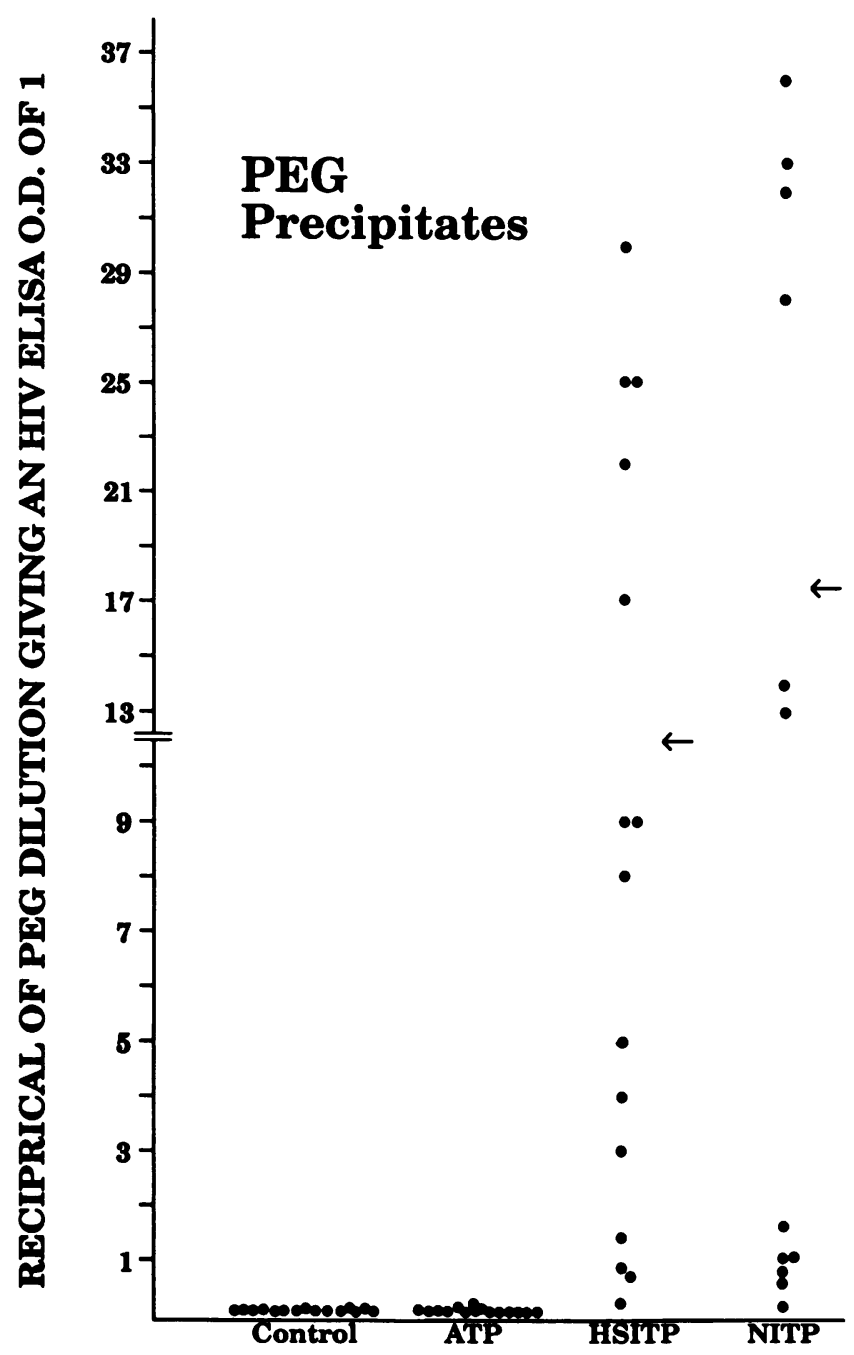

Figure 1. Ab1 of PEG-precipitable immune complexes from HIV-1ITP patients (homosexuals [HSITP] and narcotic addicts [NITP]), classic autoimmune thrombocytopenic patients $(A T P)$, and control subjects. PEG precipitates were solubilized and $2-4 \mathrm{mg} / \mathrm{ml}$ assayed for Abl by ELISA using HIV-1-coated beads. Readings $>2$ OD were suitably diluted and reassayed (see Methods). The developing antibody was anti-human IgG coupled to horseradish peroxidase. After addition of substrate, $O D$ was read at $405 \mathrm{~nm}$. Arrows refer to mean value for the group. 
ments of affinity-purified Abl but not with five control $\mathrm{F}\left(\mathrm{ab}^{\prime}\right)_{2}$ fragments using RIA (see below) and immunoblot against Ab1 bound to gp 120 but not other HIV-1 antigens (6). Similar results were obtained if the IgG was first adsorbed to a pooled normal IgG affinity column and the supernatant employed for $A b 2$ reactivity.

$\mathrm{Ab} 2$ was also prepared from PEG-precipitable immune complexes by a strategy described for $\mathrm{F}\left(\mathrm{ab}^{\prime}\right)_{2}$ antibodies (5).

$R I A$ for cross-reactive $A b 2$. The assay employed was similar to the anti- $\mathrm{F}\left(\mathrm{ab}^{\prime}\right)_{2}$ assay described previously (5). $50 \mu \mathrm{l}$ of affinity-purified $\mathrm{F}\left(\mathrm{ab}^{\prime}\right)_{2}$ fragments of $\mathrm{Abl}$ (as well as all other reagents) was applied to microtiter wells at a concentration of $200 \mathrm{ng} /$ well in PBS, blocked and washed in $3 \%$ Blotto, and then reacted with eight serial dilutions of either affinity-purified Ab2 or serum IgG starting at $200 \mathrm{ng} /$ well. Unbound Ab2 was washed away with Blotto. The wells were then reacted with ${ }^{125}$ I-labeled staphylococcal protein A (Amersham Corp., Arlington Heights, IL; $40 \mathrm{mCi} / \mathrm{mg} ; \sim 60,000 \mathrm{cpm} /$ well). Unbound ${ }^{125} \mathrm{I}$-labeled protein $\mathrm{A}$ was washed away and the bottoms of the wells were removed with a hot wire cutter and assayed for radioactivity. Antibody reactivity was determined by extrapolating the linear portion of the Ab2 serial dilution curve (usually 5-6 data points) to the baseline $x$ axis. The baseline $x$-axis represents control reactivity, e.g., $\mathrm{F}\left(\mathrm{ab}^{\prime}\right)_{2}$ plus ${ }^{125} \mathrm{I}$-labeled protein $\mathrm{A}$. Thus the lower the concentration of Ab2 intersecting the $x$-axis, the greater the reactivity of $\mathrm{Ab} 2$.

\section{Results}

Abl in PEG-precipitable immune complexes of HIV-1-ITP patients. Fig. 1 demonstrates the presence of $\mathrm{Abl}$ antibody in 14 of 15 HSITP and 12 of 13 NITP. Note the markedly elevated values $(>2.0)$ in 11 of 15 HSITP and 7 of 13 ITP patients. Negative results were obtained in 15 control subjects as well as 15 chronic ATP patients.

Gel filtration of PEG-precipitable immune complexes of $H I V-1-I T P$ patients. Fig. 2 depicts the gel filtration analysis of PEG-precipitable immune complexes of an NITP and HSITP patient. Note that $>90 \%$ of the $280-\mathrm{nm}$ reactivity is in the void volume (exclusion fraction) of a G-200 Sephadex column. This high-molecular-weight region is associated with most of the $\mathrm{Abl}$ reactivity for the NITP and HSITP patient. Some 7S IgG
Abl was also noted, which may represent partial dissociation of the complex because of dilution on the column or coprecipitation of some 7S IgG with PEG. Similar results were noted with two other NITP and two other HSITP patients (data not shown).

Binding of Abl of PEG-precipitable immune complexes to normal platelets. Fig. 3 demonstrates saturation-dependent binding of solubilized PEG-precipitable immune complexes to normal platelets, as measured by binding of ${ }^{125} \mathrm{I}$-labeled immune complexes to platelets on microtiter plates (Fig. $3 \mathrm{~A}$ ). Note inhibition of binding with a 100-fold excess of nonradioactive immune complex. Binding to platelets was also examined for $\mathrm{Abl}$ of the immune complex by elution of the bound $\mathrm{Ab} 1$ from platelets in suspension (Fig. $3 \mathrm{~B}$ ). No binding was noted with gel-filtered 7S IgG Ab1 (Fig. $3 B$ ).

Presence of Abl in a macromolecular complex of IgG, IgM, and C3. Table I depicts the macromolecular nature of the PEGprecipitable immune complex for four different patients. Thus, after incubation with insoluble protein A-Sepharose, $>98 \%$ of $\mathrm{Abl}$ reactivity and $100 \%$ of platelet-binding reactivity is removed; with insoluble anti-human IgM, > 94\% Ab1 reactivity and $37-49 \%$ of platelet-binding reactivity is removed; with insoluble anti-human $\mathrm{C} 3,>99 \% \mathrm{Abl}$ reactivity and $86-96 \%$ of platelet-binding reactivity is removed; with control Affi-Gel $10,0-4 \% \mathrm{Ab} 1$ reactivity and $0 \%$ platelet-binding reactivity is removed. Elution experiments of the bound complexes revealed $65-100 \%$ recovery of $A b 1$ and $98-103 \%$ recovery of platelet-binding reactivity for protein A and $82-96 \%$ recovery of $\mathrm{Abl}$ and $85-86 \%$ recovery of platelet-binding reactivity for anti-C3. With insoluble anti-IgM, 12-30\% of platelet-binding activity could be eluted, resulting in a total recovery of $75-93 \%$ of total platelet-binding reactivity (i.e., eluted reactivity plus residual supernatant platelet-binding reactivity).

$A b 2$ against $A b 1$ in patient sera. Ab2 was demonstrated in the sera by the reactivity of affinity-purified Ab2 of three HIV1-ITP patients with $\mathrm{F}\left(\mathrm{ab}^{\prime}\right)_{2}$ fragments of $\mathrm{Ab1}$ from three HIV1-ITP patients at the picogram level (Fig. $4 A$ ). Ab2 did not react with $\mathrm{F}\left(\mathrm{ab}^{\prime}\right)_{2}$ fragments of three healthy control subjects or

\section{PEG PRECIPITATES}

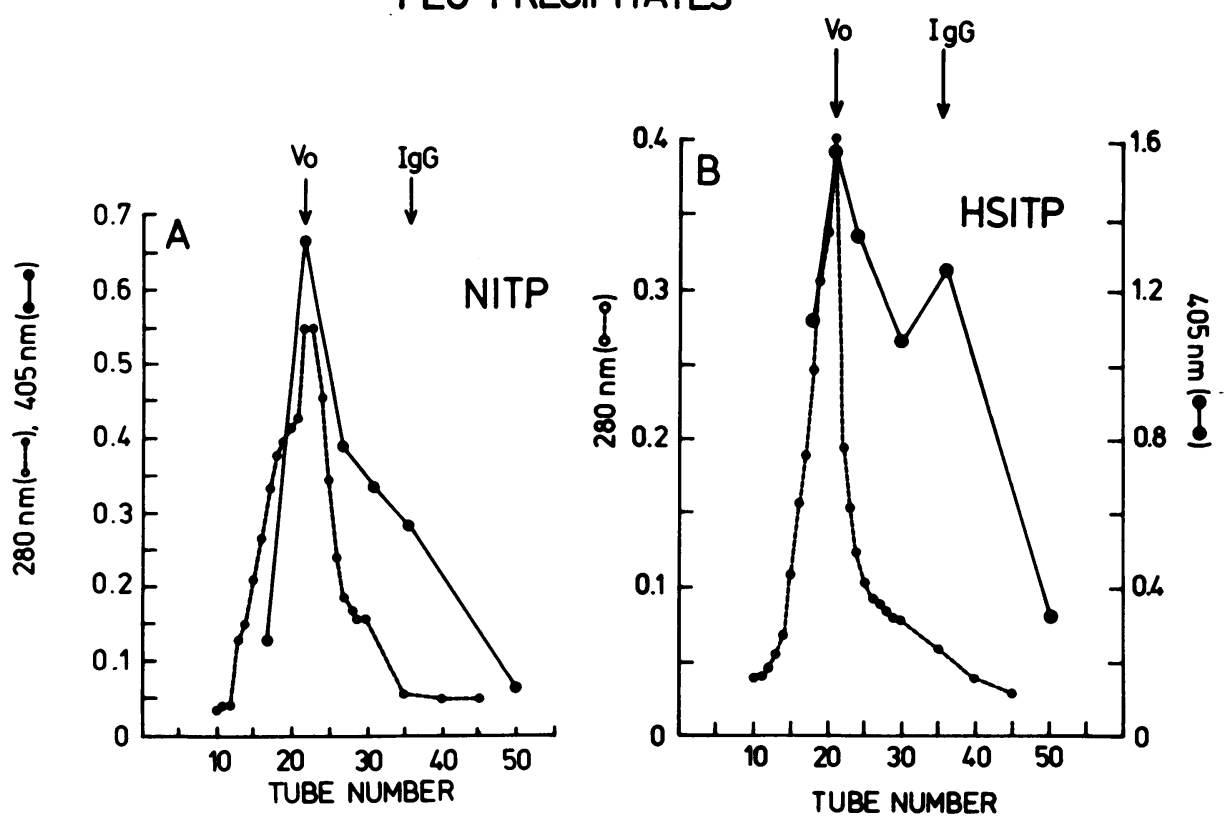

Figure 2. Effect of gel filtration on location of Abl activity in PEG-precipitable immune complexes. Solubilized immune complexes were applied to a sephadex G-200 column and the various effluents monitored for protein at $280 \mathrm{~nm}(0)$ and HIV-1 OD at 405 nm (๑). Arrows refer to void volume (Vo) and 7S IgG locations. Note the presence of $\mathrm{Abl}$ activity in the high-molecular-weight Vo fraction of an NITP and HSITP patient. 

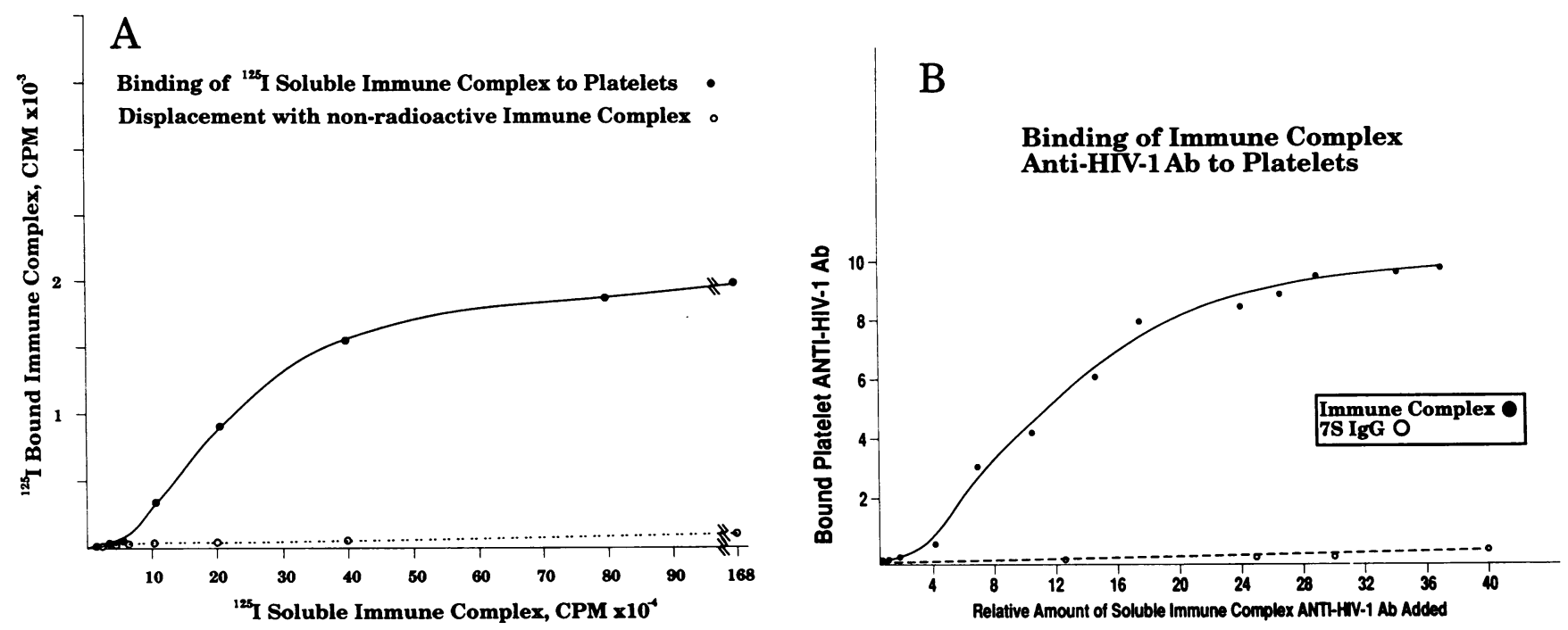

Figure 3. $(A)$ Binding of ${ }^{125}$ I-labeled, PEG-precipitable immune complex protein from patient NITP-EE to platelets. $1.2 \times 10^{6}$ washed platelets were applied to microtiter plates, blocked with Blotto, and then treated with serial dilutions of ${ }^{125}$ I-solubilized immune complex $\left(8.4 \times 10^{6}\right.$ $\mathrm{cpm} / \mu \mathrm{g})$ starting at $200 \mathrm{ng} /$ well $(\bullet-\bullet)$ or a 100:1 mixture of nonradioactive/radioactive immune complex starting at $2,000 \mathrm{ng} / \mathrm{well}(\mathrm{O}-\mathrm{O})$ for $2 \mathrm{~h}$ at room temperature. Wells were then washed and monitored for radioactivity. $(B)$ Binding of PEG-precipitable immune complex Abl from patient NITP-EE to platelets. $3.8 \times 10^{8}$ washed platelets were suspended in $250 \mu$ l of serially diluted, solubilized, PEG-precipitable immune complex (starting at $0.5 \mathrm{mg} / \mathrm{ml} ; 36.9$ reciprocal dilution, giving an HIV OD of $1 / \mathrm{ml}$ ) or $7 \mathrm{~S} \mathrm{Ig}$ (starting at $0.5 \mathrm{mg} / \mathrm{ml}$; > 40 reciprocal HIV dilution as above) and incubated for $3 \mathrm{~h}$ at $22^{\circ}$ followed by overnight incubation at $4^{\circ}$. The suspension was then applied to a $20 \%$ sucrose cushion and centrifuged to separate bound from unbound ligand. Bound Abl was eluted with acid, neutralized, and assayed by ELISA beads as in Fig. 1 for Ab1 .

from a patient with high titer anti-PLA ${ }^{1}$ antibody. IgG from five control subjects and one patient with high-titer PLA ${ }^{1}$ antibody did not react with the three $F\left(a b^{\prime}\right)_{2}$ fragments of $A b 1$ (data not shown). Of interest was the increased reactivity of autologous $\mathrm{Ab} 2$ with $\mathrm{Ab} 1$ in the three patients studied. This reactivity was 4-12-fold greater for patient A, 7-fold greater for patient $C$, and 10-120-fold greater for patient $\mathrm{D}$ compared with reactivity with homologous HIV-1-ITP patients' $\mathrm{F}\left(\mathrm{ab}^{\prime}\right)_{2}$ fragments.

Presence of Ab2 against Ab1 in PEG-precipitable immune complexes. Fig. $4 B$ demonstrates the reactivity of affinity-purified Ab2 from an NITP and an HSITP patient, respectively, with $\mathrm{F}\left(\mathrm{ab}^{\prime}\right)_{2}$ fragments of $\mathrm{Abl}$. These data are similar to those

Table I. Effect of Binding of PEG-precipitable Immune Complexes to Insoluble Staphylococcal Protein A, Anti-Igm, and Anti-C3 on Residual Anti-HIV-7 and Platelet-binding Reactivity

\begin{tabular}{|c|c|c|c|c|}
\hline \multirow[b]{2}{*}{ Patient } & \multicolumn{4}{|c|}{ Residual supernatant reactivity (elutable reactivity) } \\
\hline & Protein A & Anti-IgM & Anti-C3 & Control Affi-Gel-10 \\
\hline & \multicolumn{4}{|c|}{$\%$} \\
\hline \multicolumn{5}{|l|}{ HSITP-AA } \\
\hline Anti-HIV-1 & $<1.0(82)$ & 4.9 (ND) & $<1.0(96)$ & $96(0)$ \\
\hline Platelet binding & $0(103)$ & $63(12)$ & $14.0(86)$ & $100(0)$ \\
\hline \multicolumn{5}{|l|}{ HSITP-BB } \\
\hline Anti-HIV-1 & ND & ND & $<1.0(82)$ & ND \\
\hline Platelet binding & $0(100)$ & $63(30)$ & 4.0 (ND) & $100(0)$ \\
\hline \multicolumn{5}{|l|}{ NITP-CC } \\
\hline Anti-HIV-1 & $1.1(65)$ & 5.4 (ND) & $<1.0(96)$ & $107(0)$ \\
\hline Platelet binding & $0(102)$ & $51(28)$ & $5.0(85)$ & $100(0)$ \\
\hline \multicolumn{5}{|l|}{ NITP-DD } \\
\hline Anti-HIV-1 & $<1.0(65)$ & 2.0 (ND) & $<1.0(85)$ & $103(0)$ \\
\hline Platelet binding & $0(98)$ & $62(14)$ & $12(86)$ & $100(0)$ \\
\hline
\end{tabular}

Solubilized, PEG-precipitable immune complexes were incubated with insoluble staphylococcal protein A, anti-human IgM and anti-human C3 antibody, as well as control Affi-Gel 10, overnight; and the residual supernatant was assayed for anti-HIV-1 as well as platelet-binding reactivity. Numbers in parentheses refer to percent acid-elutable reactivity from bound Affi-Gel. ND refers to not done. 

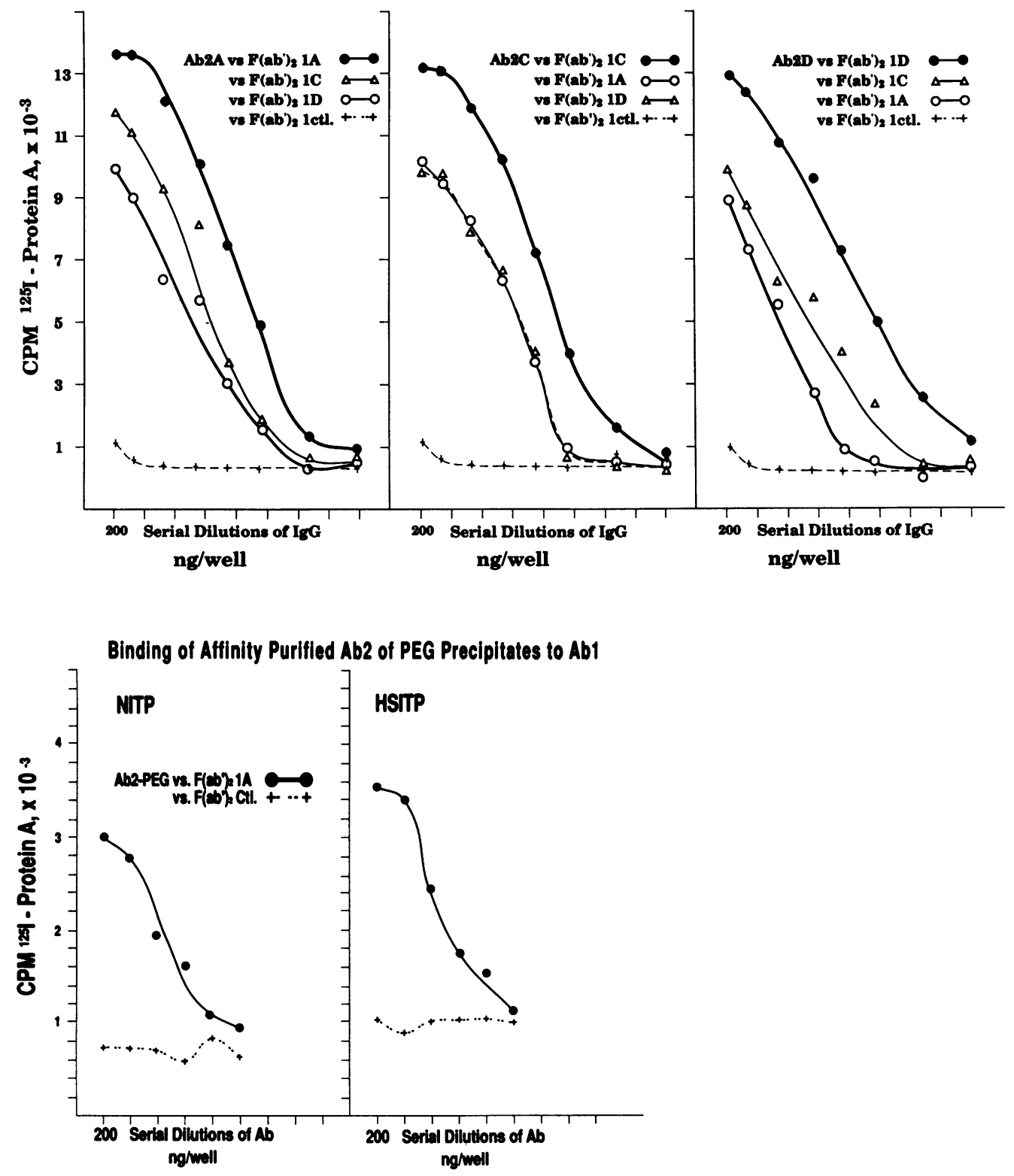

Figure 4. $(A)$ Binding of affinity-purified $\mathrm{Ab} 2$ to $\mathrm{F}\left(\mathrm{ab}^{\prime}\right)_{2}$ fragments of affinity-purified $\mathrm{Ab} 1 . \mathrm{F}\left(\mathrm{ab}^{\prime}\right)_{2}$ fragments of Ab1 from HSITP patients A and $\mathrm{D}$ and NITP patient $\mathrm{C}$ as well as control subject $(1 \mathrm{ctl})$ were applied to microtiter plates at a concentration of $2,000 \mathrm{ng} /$ well and blocked and washed with Blotto. Serial doubling dilutions of $\mathrm{Ab} 2$ starting at $200 \mathrm{ng} /$ well were then applied. Unbound Ab2 was washed away with Blotto and bound $\mathrm{Ab} 2$ assayed with ${ }^{125} \mathrm{I}$-staphylococcal protein $\mathrm{A}$. $(B)$ Binding of affinity-purified Ab2 of PEG precipitates to $F\left(a^{\prime}\right)_{2}$ fragments of $A b 1$ from patient serum. Affinity-purified $F\left(a^{\prime}\right)_{2}$ fragments of $A b 1$ from patient HSITP-A serum were applied to microtiter plates and then reacted with affinity-purified intact Ab2 from the PEG precipitate of patients NITP-R and HSITP-J.

obtained with $\mathrm{Ab} 2$ and $\mathrm{Ab} 1$ affinity purified from sera (Fig. $4 A$ ).

Correlation of Ab2 with PEG-precipitable immune complexes and thrombocytopenia. Purified IgG from 10 NITP patients and 11 HSITP patients was tested for its reactivity with $\mathrm{F}\left(\mathrm{ab}^{\prime}\right)_{2}$ fragments of affinity-purified Ab1 from an NITP and an HSITP patient. All $21 \mathrm{IgG}$ fractions reacted with both $\mathrm{F}\left(\mathrm{ab}^{\prime}\right)_{2}$ fragments, whereas 5 control IgG fractions showed no reactivity (Table II). HIV-1-ITP patients' $\mathrm{Ab} 2$ reactivity varied in HSITP patients from a detection sensitivity at $33-80 \mathrm{pg}$ for patient $\mathrm{J}$ to $4,440 \mathrm{pg}$ for patient $\mathrm{I}$; in NITP patients the values ranged from 44-110 pg for patient $U$ to $2,400-3,820 \mathrm{pg}$ for patient $\mathrm{Y}$. The degree of reactivity of the $\mathrm{Ab} 2$ of the individual patients was very similar with both $\mathrm{Ab} 1 \mathrm{~F}\left(\mathrm{ab}^{\prime}\right)_{2}$ preparations tested. Similar studies were performed on nonthrombocytopenic $(>168,000 / \mu$ l platelet count) HIV-1-seropositive homosexuals (five subjects) and narcotic addicts (five subjects). They were found to have barely detectable levels of $\mathrm{Ab} 2$ at concentrations of 20 to $200 \mathrm{ng}$.

A $\log$ - $\log$ correlation analysis of PEG-precipitable immune complexes versus $\mathrm{Ab} 2$ reactivity revealed a significant correlation for both homosexuals $(\mathrm{r}=0.95, P<0.001 ; 28$ measurements on 14 individuals) and narcotic addicts $(r=0.95, P$ $<0.001 ; 31$ measurements on 16 individuals). Similar correlations were noted for $\mathrm{Ab} 2$ reactivity and thrombocytopenia for homosexuals $(r=0.90, P<0.001)$ and narcotic addicts $(r$ 


\begin{tabular}{|c|c|c|c|c|c|c|c|c|c|c|c|}
\hline \multirow[b]{2}{*}{$\mathrm{Abl}-\mathrm{F}(\mathrm{ab})_{2}$} & \multicolumn{11}{|c|}{ Detection sensitivity of HSITP serum IgG, Ab2 } \\
\hline & $\mathrm{E}$ & $\mathbf{F}$ & G & $\mathbf{H}$ & I & $\mathbf{J}$ & $\mathbf{K}$ & $\mathbf{L}$ & $\mathbf{M}$ & $\mathrm{N}$ & $\mathrm{C} 1-\mathrm{C} 5$ \\
\hline NITP-A & 2960 & 880 & 83 & 440 & 4440 & 33 & 260 & 210 & 720 & 440 & 0 \\
\hline \multirow[t]{3}{*}{ HSITP-D } & 3360 & 1600 & 110 & 1320 & 4440 & 80 & 300 & 170 & 880 & 440 & 0 \\
\hline & \multicolumn{11}{|c|}{ Detection sensitivity of NITP serum IgG, Ab2 } \\
\hline & 0 & $\mathbf{P}$ & Q & $\mathbf{R}$ & $\mathbf{S}$ & $\mathbf{T}$ & $\mathrm{U}$ & $\mathbf{v}$ & w & $\mathrm{x}$ & $\mathbf{Y}$ \\
\hline NITP-A & 760 & 280 & 480 & 190 & 1920 & 1120 & 110 & 50 & 1600 & 1160 & 3820 \\
\hline HSITP-D & 2080 & 460 & 220 & 480 & 3040 & 800 & 44 & 50 & 1280 & 1760 & 2400 \\
\hline
\end{tabular}

A solid-phase ${ }^{125}$ I-labeled protein A assay was used to determine the sensitivity of affinity-purified Ab2 for the detection of $F\left(a b^{\prime}\right)_{2}$ fragments of affinity-purified Ab1 at $200 \mathrm{ng} /$ well. Serum IgG was serially diluted at doubling dilutions for the detection of Ab2, starting at 200 ng/well. The linear portion of the curve was extrapolated to the baseline $x$-axis, which represented control reactivity, e.g., $\mathrm{F}\left(\mathrm{ab}^{\prime}\right)_{2}$ plus ${ }^{125} \mathrm{I}$-labeled protein $\mathrm{A}$. The concentration of $\mathrm{Ab} 2$ intersecting this baseline represents the detection sensitivity of the assay and is given in picograms/well. $\mathrm{Cl}-\mathrm{C} 5 \mathrm{refer}$ to five different control IgG's.

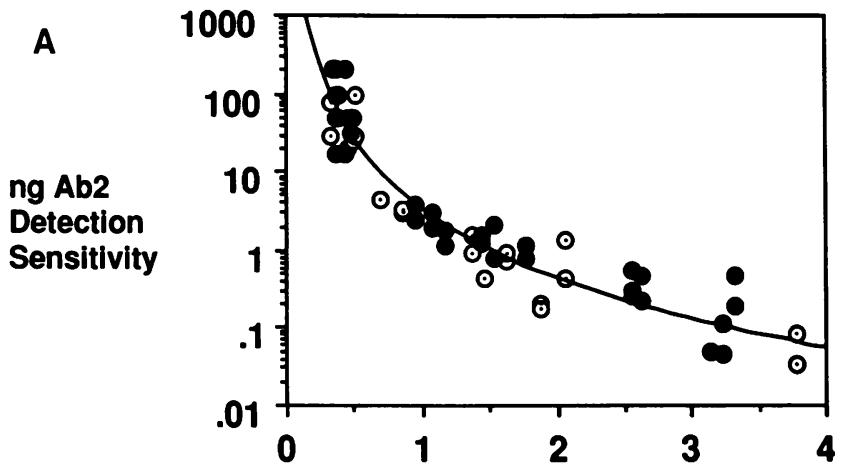

PEG immune complexes, $\mathbf{m g} / \mathbf{m l}$

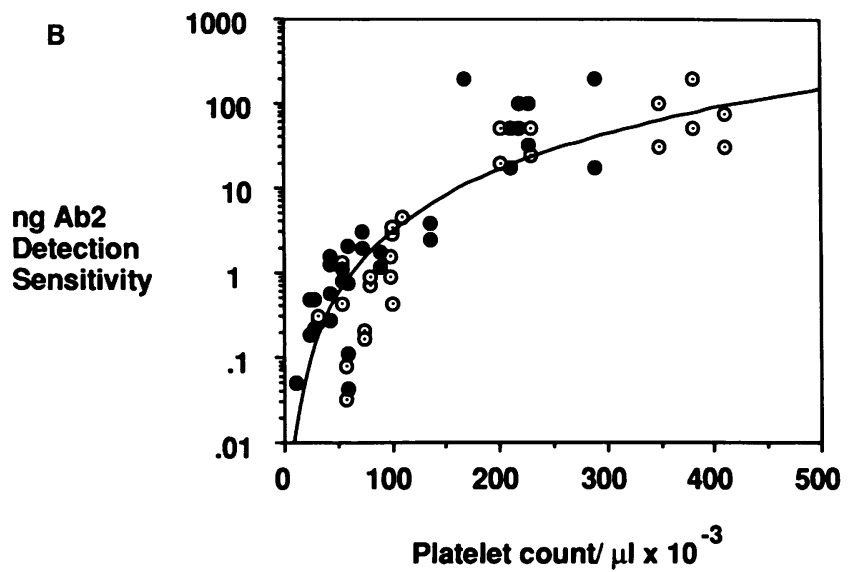

Figure 5. Correlation of Ab2 with $(A)$ PEG-precipitable immune complex levels $(\mathrm{r}=0.91, P<0.001)$ and $(B)$ platelet count $(\mathrm{r}=0.89$, $P<0.001)$. The data from 59 paired measurements of HIV-1-seropositive homosexuals $(0)$ and narcotic addicts $(\bullet)$ is presented as a semilog plot. The data include measurements from 10 nonthrombocytopenic HIV-1-seropositive subjects in addition to 21 of the thrombocytopenic patients of Table II. ng Ab2 detection sensitivity refers to the lowest concentration of Ab2 capable of reacting with $\mathrm{F}\left(\mathrm{ab}^{\prime}\right)_{2}$ fragments of $\mathrm{Abl}$.
$=0.87, P<0.001)$. Fig. $5, A$ and $B$, depicts semilog plots of the individual data points for all 59 measurements on $30 \mathrm{HIV}-1$ seropositive homosexuals and narcotic addicts.

Presence of Abl in PEG-precipitable immune complexes. Further experiments were performed to determine whether $\mathrm{Abl}$ was present in the PEG-precipitable immune complexes of HSITP and NITP patients. This was accomplished with acid elution by a strategy previously described (5). Fig. 6 demonstrates the immunoblots obtained with affinity-purified Abl from an HSITP and an NITP patient, respectively, on nitrocellulose strips containing multiple HIV-1 antigens. Note reactivity of $A b 1$ with a gp 120 band (lanes $A 2$ and $B 2$ ). Note reactivity of the patient's serum with numerous HIV-1 antigens (lane A1). (The remainder of the figure is cited below, under Reactivity of $\mathrm{Ab} 1$ and $\mathrm{Ab} 2$ with gp120 immunoblot.)

Binding of $A b 1$ and $A b 2$ derived from sera to platelets. As noted previously (6), affinity-purified Ab1 did not bind to platelets at a concentration as high as $70 \mu \mathrm{g} / \mathrm{ml}$. Affinity-purified $\mathrm{Ab} 2$ also had no reactivity at a concentration of $7 \mu \mathrm{g} / \mathrm{ml}$. However, the combination of both antibodies (preincubated at $22^{\circ} \mathrm{C}$ for $2 \mathrm{~h}$ ) did bind to platelets, whether the antibodies were obtained from the same patient (Fig. 7) or from two different patients (data not shown). Optimum binding to platelets was noted at Ab1/Ab2 ratios of 5:1 and 10:1 with Ab2 held constant and at 10:1 and 20:1 with Ab1 held constant.

Fig. 8 demonstrates binding of affinity-purified $A b 1$ and $\mathrm{Ab} 2$ derived from PEG-precipitable immune complexes to platelets. Preincubation of $\mathrm{Ab} 1$ and $\mathrm{Ab} 2\left(2 \mathrm{~h}\right.$ at $\left.22^{\circ} \mathrm{C}\right)$ resulted in an immune complex capable of binding to platelets in a concentration-dependent manner. $\mathrm{Ab} 1$ alone or $\mathrm{Ab} 2$ alone did not bind to platelets. These results are similar to those noted for affinity-purified $\mathrm{Ab} 1$ and $\mathrm{Ab} 2$ from sera (Fig. 7).

Reactivity of $A b 1$ and $A b 2$ from $P E G$ precipitates with gp120 on immunoblot. To determine whether Ab2 was internal-image type antiidiotype antibody, experiments were performed on immunoblot to determine whether Ab2 would block the binding of Ab1 to gp 120. This was not observed. On the contrary, $A b 2$ and $A b 1$ intensified the binding of the enzyme-conjugated anti-human indicator antibody to gp120 when both antibodies were added together (Fig. 6, lanes $A 7-A 9$ 

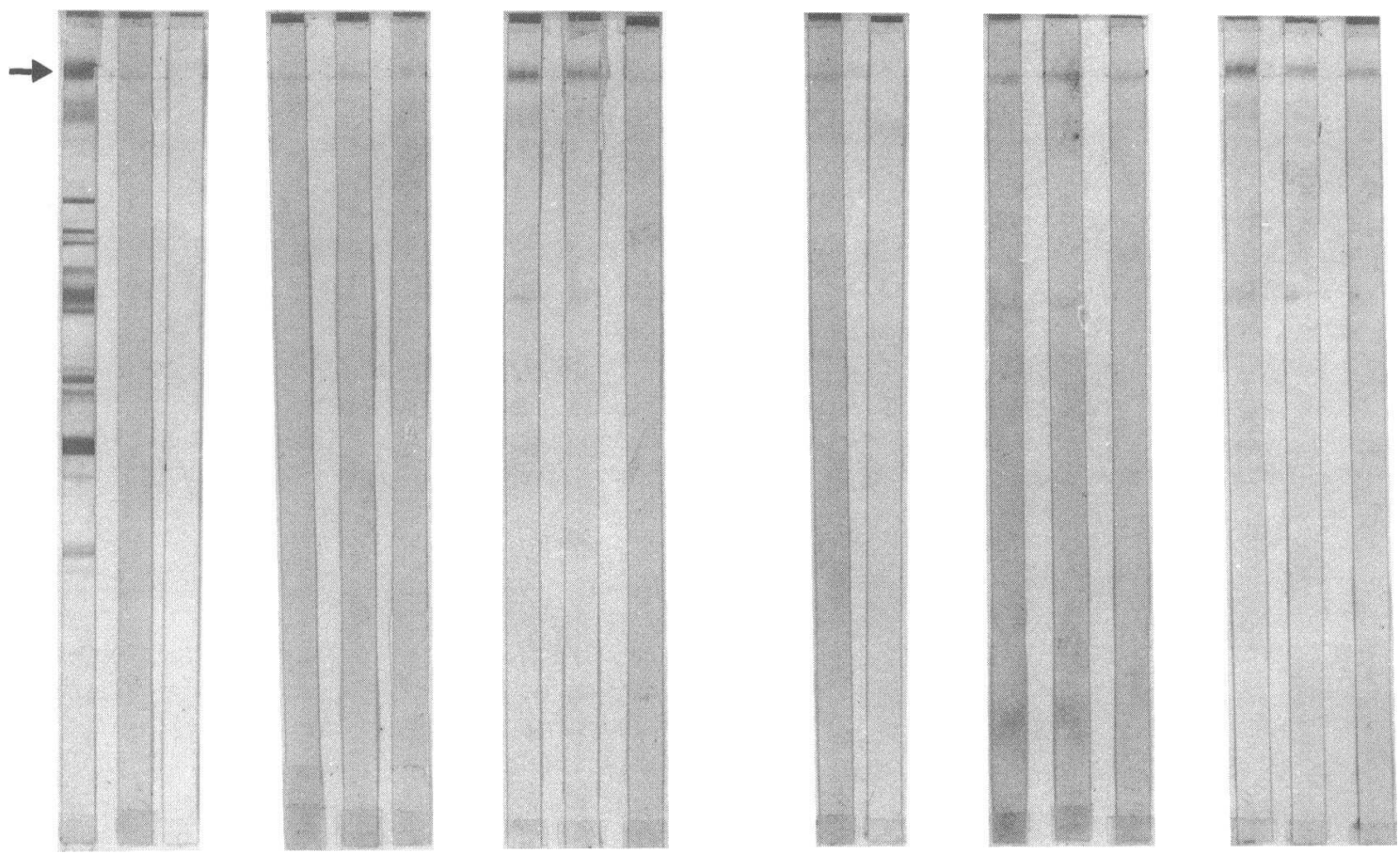

Figure 6. Immunoblot of $\mathrm{Ab1}$ and $\mathrm{Ab} 2$ affinity purified from PEG-precipitable immune complexes. Ab1, Ab2, and preincubated Ab1 plus Ab2 were applied to nitrocellulose strips containing the HIV-1 antigens. Reactivity was detected by ELISA with an anti-human IgG antibody coupled to horseradish peroxidase. (A) Patient NITP-R. (B) Patient HISTP-J. Lane $A 1$ represents reactivity of HIV-positive sera at a 1:50 dilution; lane $A 2$, Abl at $0.074 \mu \mathrm{g} / \mathrm{ml}$; lane A3, Ab2 at $0.74 \mu \mathrm{g} / \mathrm{ml}$; lanes $A 4-A 6, \mathrm{Ab} 1$ at $0.074 \mu \mathrm{g} / \mathrm{ml}$ plus irrelevant $\mathrm{IgG}$ at $0.74,0.38$, and $0.19 \mu \mathrm{g} / \mathrm{ml}, \mathrm{re}-$ spectively; lanes $A 7-A 9, \mathrm{Abl}$ at $0.074 \mu \mathrm{g} / \mathrm{ml}$ plus $\mathrm{Ab} 2$ at $0.74,0.38$, and $0.19 \mu \mathrm{g} / \mathrm{ml}$, respectively. $B$ is similar to $A$, except for an $\mathrm{Abl}$ concentration of $0.27 \mu \mathrm{g} / \mathrm{ml}$ with similar ratios of $\mathrm{Ab} 2$ and irrelevant $\mathrm{IgG}$. Arrow refers to gp120 location.

Binding of Affinity Purified Anti-HIV-1 (gp120):Ab1 and Anti-Anti-HIV-1 (gp120):Ab2 to Platelets

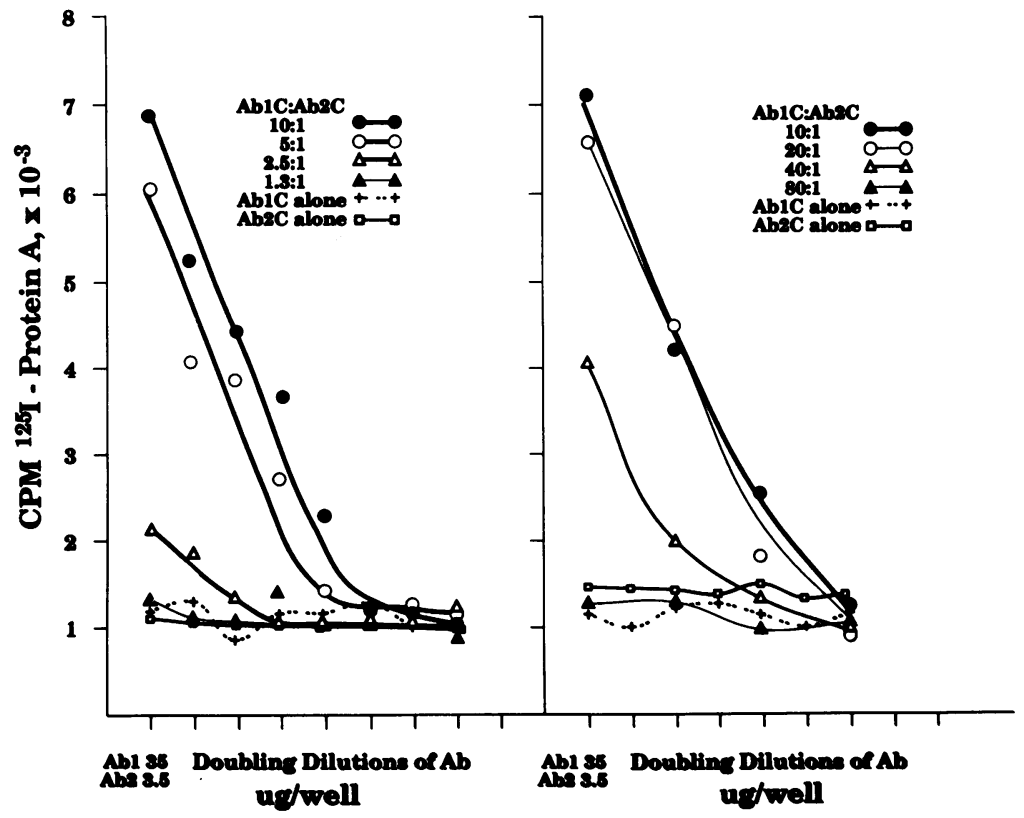

Figure 7. Binding of affinity-purified $\mathrm{Ab} 1$ and $\mathrm{Ab} 2$ from patient sera to platelets. $10^{7}$ washed platelets were applied to microtiter plates, blocked and washed with $3 \%$ Blotto, and then reacted with $A b 1, A b 2$, or a combination of $A b 1$ plus $\mathrm{Ab} 2$ (preincubated for $2 \mathrm{~h}$ at $22^{\circ} \mathrm{C}$ at various ratios). Non-adherent $\mathrm{Ab}$ was washed away and adherent antibody monitored with ${ }^{125}$ I-labeled staphylococcal protein A. (Left) Top curve (๑) represents Ab1/Ab2 at a protein ratio of 10:1 (i.e., 35:3.5 $\mu \mathrm{g} /$ well). The bottom curves represent $\mathrm{Ab} 2$ held constant at $3.5 \mu \mathrm{g} /$ well and $\mathrm{Ab1}$ diluted to result in ratios of 5:1 (o), 2.5:1 ( $\Delta$ ), and 1.3:1 ( $\Delta$ ) before doubling dilutions of the complex onto platelets. (Right) Ab1 was held constant at $35 \mu \mathrm{g} /$ well and $\mathrm{Ab} 2 \mathrm{di}-$ luted to result in ratios of 20:1 (o), 40:1 ( $\Delta$ ), and 80:1 ( $\Delta)$. 
Binding of Affinity Purified Ab1 and Ab2 of PEG Precipitates to Platelets

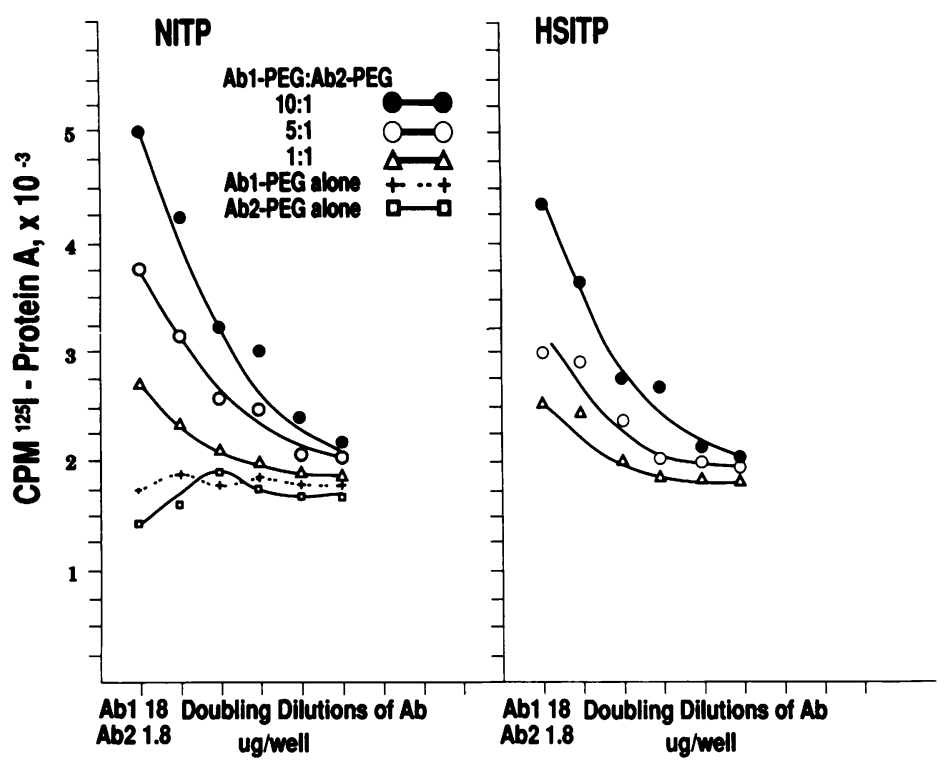

Figure 8. Binding of affinity-purified $\mathrm{Ab} 1$ and $\mathrm{Ab} 2$ of PEG-precipitable immune complexes to platelets of patients NITP-R and HSITP-J. Ab1 and Ab2 and their combination (after preincubation) were reacted with washed platelets on a microtiter plate as in Fig. 7. Abl was held constant. The ratio of $\mathrm{Abl} / \mathrm{Ab} 2$ was 10:1 (i.e., 18:1.8 $\mu \mathrm{g} /$ well) $(\bullet), 5: 1(0)$, and 1:1 $(\Delta)$, before doubling dilutions of the complex onto platelets. and $B 7-B 9$ ). Compare to control lanes $A 4-A 6$ and $B 4-B 6$ in which $\mathrm{Abl}$ was added together with irrelevant $\mathrm{IgG}$.

\section{Discussion}

PEG-precipitable serum protein is three- to sevenfold greater in HIV-1-ITP patients than in either normal subjects or classic ATP patients $(2,4)$. Platelet-bound IgG and $\mathrm{C} 3 \mathrm{C} 4$ are three- to fourfold greater and platelet-bound IgM two- to threefold greater than in normal subjects $(2,4)$. It has recently been shown that platelets of HIV-1-ITP patients contain elutable $\mathrm{Abl}$ in the absence of HIV-1 antigen and that the Abl is present as a high-molecular-weight complex (6). In addition, the sera of these patients contain public anti- $\mathrm{F}\left(\mathrm{ab}^{\prime}\right)_{2}$ antibodies (5). It has been suggested, via qualitative studies on immunoblot, that some of these anti-F( $\left(\mathrm{ab}^{\prime}\right)_{2}$ antibodies may be antiidiotypes against Abl (6). Thus, an attractive hypothesis for the marked deposition of $\mathrm{Ig}$ and $\mathrm{C}$ on these platelets is the deposition of immune complexes containing Ab1-Ab2 complexes, presumably present in the PEG-precipitable material, onto platelets; thrombocytopenia could result at least in part from phagocytosis of opsonized platelets by monocytes and fixed macrophages. Alternatively, or in addition, there is evidence that thrombopoiesis can be impaired (12-16), possibly via direct invasion of megakaryocytes with HIV-1 virus $(17,18)$ or possibly via immune complex-mediated megakaryocyte damage.

In this report, we have carefully examined the PEG-precipitable protein in HIV-1-ITP patients for its Ig composition, Abl reactivity, and ability to bind to platelets. Gel filtration studies demonstrate that $>90 \%$ of the precipitable protein is present as a high-molecular-weight complex containing Abl ruling out the possibility that the elevated values of PEG-precipitable complexes in these patients are due to precipitation of 7S IgG in hypergammaglobulinemic patients. The Ab1 reactivity of the high-molecular-weight complex binds to platelets in a saturation-dependent manner. This high-molecular-weight complex contains $\mathrm{IgG}, \mathrm{IgM}, \mathrm{C} 3$, and $\mathrm{Ab} 1$ reactivity in the absence of HIV-1 antigen (6). Affinity chromatography with protein A,
anti-IgM, and anti-C 3 columns reveals that $\sim 95 \%$ of the $\mathrm{Abl}$ reactivity in the $\mathrm{PEG}$-precipitable protein is present as a macromolecular complex of IgG, IgM, and C3. Almost all of the IgG, $86-96 \%$ of the C3, and $37-49 \%$ of the IgM binds to platelets. Thus, some of the IgM contains Abl reactivity and does not bind to platelets, possibly because it is not present as a macromolecular complex.

Because of the suggestion from qualitative immunoblot studies (6) that $\mathrm{Ab} 1$ might be present as an $\mathrm{Ab1}-\mathrm{Ab} 2$ complex in HIV-1-ITP patients, their sera and PEG-precipitable immune complexes were examined for Ab2 by use of a highly sensitive quantitative immunoassay. Abl was affinity purified with recombinant gp120 and Ab2 was affinity purified with Ab1. 21 consecutive HIV-1-ITP patients with elevated PEGprecipitable immune complexes (10 HSITP and 11 NITP patients) had detectable $\mathrm{Ab} 2$ in their sera, whereas 10 consecutive nonthrombocytopenic HIV-1-seropositive subjects had barely detectable levels and 5 consecutive control subjects had no detectable Ab2. In addition, Ab2 could be eluted from their PEGprecipitable immune complexes, and there is a significant correlation of $\mathrm{Ab} 2$ reactivity with circulating immune complex level. A similar correlation has been reported for nonspecific anti-F( $\left(\mathrm{ab}^{\prime}\right)_{2}$ antibodies in these patients (5). Abl could also be eluted from their PEG-precipitable immune complexes. Thus anti-F $\left(\mathrm{ab}^{\prime}\right)_{2}$ antiidiotype-like HIV-1 Ab complexes circulate in the sera of HIV-1-ITP patients and deposit on their platelets.

Since Ab2 did not block the binding of Ab1 to its epitope, one should consider the possibility that Ab2 may be directed against the framework region of Fab rather than acting as a true antiidiotypic $\mathrm{Ab}$. In that case, the lack of reactivity of $\mathrm{Ab} 2$ with $\mathrm{F}\left(\mathrm{ab}^{\prime}\right)_{2}$ from control preparations would suggest that $\mathrm{Abl}$ in these patients tends to use an uncommon $\mathrm{VH}$ and/or VK region, not much represented in normal IgG. The greater reactivity of $\mathrm{Ab} 2$ for autologous than for homologous $\mathrm{F}\left(\mathrm{ab}^{\prime}\right)_{2} \mathrm{Ab} 1$ could then be explained on the basis of somatic mutations unique to the $\mathrm{Ab} 1$ of that individual. Indeed, although $\mathrm{Ab} 2$ reacted with $A b 1$ from different patients, its reactivity with autologous Ab1 was 4-120-fold greater than its reactivity with 
homologous Abl. Thus, the patients demonstrated greater auto- than cross-reactive $\mathrm{Ab} 2$ reactivity. These data indicate that the $\mathrm{Ab} 2$ produced by a patient are directed against autologous $\mathrm{Ab} 1$ idiotypes as well as against idiotypes shared by different patients, producing antibodies against similar or identical gp120 epitopes.

Regardless of the exact specificity, it is evident that $\mathrm{Abl}$ and Ab2 are responsible for immune complex formation and deposition on platelets. Evidence for deposition of immune complexes on platelets was obtained in vitro by the demonstration that $(a)$ PEG-precipitable complexes bind to platelets in a saturation-dependent manner and $(b)$ affinity-purified $\mathrm{Abl}$ and $\mathrm{Ab} 2$ do not bind to platelets independently but do bind as a complex in a saturation-dependent manner and ex vivo by the demonstration that $\mathrm{Ab} 1$ and $\mathrm{Ab} 2$ can be eluted from platelets and $\mathrm{Ab} 2$ shown to react on immunoblot with $\mathrm{Abl}(6)$.

The ability of PEG-precipitable immune complexes as well as affinity-purified $\mathrm{Ab} 1-\mathrm{Ab} 2$ complexes to bind to platelets in vitro, and the ex vivo presence of these complexes on platelets (6), suggests that they may be responsible for or contribute to the markedly elevated Ig content of these platelets. The likely presence of free $\mathrm{Fc}$ and $\mathrm{C} 3$ domains in the macromolecular complexes suggests that they may be cleared by the patient's reticuloendothelial system via $\mathrm{Fc}$ and $\mathrm{C} 3 \mathrm{~b}$ receptors. This suggestion is supported by the significant positive correlation between $\mathrm{Ab} 2$ reactivity (i.e., idiotype antiidiotype formation) and thrombocytopenia and by the clinical response of HIV-1-ITP patients to corticosteroids, splenectomy, or intravenous gamma globulin-agents or procedures that block reticuloendothelial clearance. The ability of immune complexes to induce thrombocytopenia is supported by experimental studies in rabbits, wherein thrombocytopenia was induced by immune complex infusion $(19,20)$, as well as by a clinical study of thrombocytopenia in patients with classic immune complex disease (SLE), which demonstrated the presence of pepsin-sensitive immune complexes in their sera that were capable of binding to normal platelets in the absence of pepsin digestion (21).

Thus, HIV-1-ITP patients have circulating anti-idiotypelike HIV-1 antibody complexes that are present in a PEG-precipitable macromolecular complex and capable of binding to platelets in a saturation-dependent manner. It is likely that this is responsible, at least in part, for the markedly elevated platelet Ig content of their platelets. We postulate that this may be responsible for their peripheral platelet destruction.

\section{Acknowledgments}

The authors are indebted to Dr. Jeanette Thorbecke for helpful discussions, Dr. Scott D. Putney of Repligen (Cambridge, MA) for the generous supply of recombinant gp 120, Mr. Gene Shultz for computer drawings of the figures, and Evelyn Marrero for typing the manuscript.

This study was supported by grants HL-13336-20 of the National
Heart, Lung, and Blood Institute, DA-04315-04 of the National Institute of Drug Abuse and the Boulanger-Glazier Immunology Research Fund.

\section{References}

1. Morris, L., A. Distenfeld, E. Amorosi, and S. Karpatkin. 1982. Autoimmune thrombocytopenic purpura in homosexual men. Ann. Intern. Med. 96:714-717.

2. Savona, S., M. A. Nardi, E. T. Lennette, and S. Karpatkin. 1985. Thrombocytopenic purpura in narcotics addicts. Ann. Intern. Med. 102:737-741.

3. Ratnoff, O. D., J. E. Menitove, R. H. Aster, and M. M. Lederman. 1983. Coincident classic hemophilia and 'idiopathic' thrombocytopenic purpura in patients under treatment with concentrates of anti-hemophilic factor (Factor VIII). N. Engl. J. Med. 308:439-442.

4. Walsh, C. M., M. A. Nardi, and S. Karpatkin. 1984. On the mechanism of thrombocytopenic purpura in sexually-active homosexual men. N. Engl. J. Med. 311:635-639.

5. Yu, J.-R., E. T. Lennette, and S. Karpatkin. 1986. Anti-F(ab' $)_{2}$ antibodies in thrombocytopenic patients at risk for acquired immunodeficiency syndrome. J. Clin. Invest. 77:1756-1761.

6. Karpatkin, S., M. Nardi, E. T. Lennette, B. Byrne, and B. Poiesz. 1988. Anti-human immunodeficiency virus type 1 antibody complexes on platelets of seropositive thrombocytopenic homosexuals and narcotic addicts. Proc. Natl. Acad. Sci. USA. 85:9763-9767.

7. Karpatkin, S., and M. A. Nardi. 1988. Immunologic thrombocytopenic purpura in human immunodeficiency virus-seropositive patients with hemophilia. Comparison with patients with classic autoimmune thrombocytopenia purpura, homosexuals with thrombocytopenia, and narcotic addicts with thrombocytopenia. J. Lab. Clin. Med. 111:441-448.

8. Stricker, R. B., D. I. Abrams, L. Corash, and M. A. Shuman. 1985. Target platelet antigen in homosexual men with immune thrombocytopenia. $N$. Engl. J. Med. 313:1375-1380.

9. Van der Lelie, J., J. M. A. Lange, J. J. E. Vos, C. M. Van Dalen, S. A. Danner, and A. E. G. Kr. Von dem Borne. 1987. Autoimmunity against blood cells in human immunodeficiency virus (HIV) infection. Br. J. Haematol. 67:109-114.

10. Lyman, B., L. Rosenberg, and S. Karpatkin. 1971. Biochemical and biophysical aspects of human platelet adhesion to collagen fibers. J. Clin. Invest. 50:1854-1863.

11. Johnson, D. A., J. W. Gautsch, J. R. Sportsman, and J. H. Elder. 1984. Improved technique utilizing nonfat milk for analysis of proteins and nucleic acids transferred to nitrocellulose. Gene Anal. Tech. 1:3-8.

12. Hymes, K. B., J. B. Greene, and S. Karpatkin. 1988. The effect of azidothymidine on HIV-related thrombocytopenia. N. Engl. J. Med. 318:516.

13. Swiss Group for Clinical Studies on AIDS. 1988. Zidovudine for the treatment of thrombocytopenia associated with HIV. A prospective study. Ann. Intern. Med. 109:718-721.

14. Siegel, R. S., J. L. Rae, and C. M. Kessler. 1986. Immune thrombocytopenic purpura in HTLV-III men. Blood. 68(Suppl. 1):134A. (Abstr.)

15. Ballem, P., A. Belzberg, D. Devine, and N. Buskard. 1988. Pathophysiology of HIV-1-ITP and the mechanism of the response to AZT. Blood. 72(Suppl. 1):261A. (Abstr.)

16. Stella, C. C., A. Ganser, and D. Hoezler. 1987. Defective in vitro growth of the hemopoietic progenitor cells in the acquired immunodeficiency syndrome. $J$. Clin. Invest. 80:286-293.

17. Basch, R. S., Y. H. Kouri, and S. Karpatkin. 1990. Expression of CD4 by human megakaryocytes. Proc. Natl. Acad. Sci. USA. 87:8085-8089.

19. Parbtani, A., R. L. Kinlough-Rathbone, A. Chahil, M. Richardson, and J. F. Mustard. 1990. Survival of rabbit platelets exposed to immune complexes. Exp. Mol. Pathol. 52:109-121.

20. Miescher, P., and R. Straessle. 1956. Experimentell Studien uber den Mechanismus der Thrombocyten-Schadigung durch Antigen-Antikorper-Reaktionen. Vox Sang. 1:83-94.

21. Endressen, G. K. M., and O. Foerre. 1982. Studies in the binding of immunoglobulins and immune complexes to the surface of human platelets: $\mathrm{IgG}$ molecules react with platelet $\mathrm{Fc}$ receptors with the $\mathrm{CH} 3$ domain. Int. Arch. Allergy Appl. Immunol. 67:33-39. 